\title{
Large- Scale Analysis of MicroRNA Expression in Motor Neuron- like Cells derived from Human Umbilical Cord Blood Mesenchymal Stem Cells
}

\section{Davood Sanooghi}

Shahid Beheshti University

Abolfazl Lotfi

Vocational and Training University

Faezeh Faghihi ( $\nabla$ faezefaghihi@yahoo.com)

Iran University of Medical Sciences https://orcid.org/0000-0003-1657-6242

Afzal Karimi

Iran University of Medical Sciences

\section{Zohreh Bagher}

Iran university of Medical Sciences

\section{Behnam Yousefi}

Iran university of medical sciences

\section{Erfan Lotfi}

Birjand University of Medical Sciences

Mohammad Taghi Joghataei

Iran University of Medical Sciences

\section{Research article}

Keywords: MicroRNA, Motor neuron, Mesenchymal Stem cell, Cord blood

Posted Date: March 11th, 2020

DOI: https://doi.org/10.21203/rs.3.rs-16565/v1

License: (c) (1) This work is licensed under a Creative Commons Attribution 4.0 International License. Read Full License

Version of Record: A version of this preprint was published at Scientific Reports on April 7th, 2022. See the published version at https://doi.org/10.1038/s41598-022-09368-6. 


\section{Large- Scale Analysis of MicroRNA Expression in Motor Neuron- like Cells derived from Human Umbilical Cord Blood Mesenchymal Stem Cells}

Davood Sanooghi ${ }^{1, \#}$, Abolfazl Lotfi ${ }^{2, \#}$, Faezeh Faghihi ${ }^{3,4, *}$, , Afzal Karimi ${ }^{5}$, Zohreh Bagher6, Behnam Yousefi ${ }^{3}$, Erfan Lotfi ${ }^{7}$, Mohammad Taghi Joghataei, ${ }^{3,8}$,

${ }^{1}$ Department of Genetics, Faculty of Biological Sciences, Shahid Beheshti University, Tehran, Iran.

${ }^{2}$ Agricultural College of Damavand, Technical and Vocational University, Tehran, Iran.

${ }^{3}$ Cellular and Molecular Research Center, Iran University of Medical Sciences, Tehran, Iran.

${ }^{4}$ Pad Nahad Tabiat, Ltd. Company, Tehran, Iran.

${ }^{5}$ Department of Biotechnology, Faculty of Advanced Technologies in Medicine, Iran University of Medical Sciences, Tehran, Iran.

${ }^{6}$ ENT and Head \& Neck Research Center and Department, the Five Senses Institute, Hazrat Rasoul Akram Hospital, Iran University of Medical Sciences, Tehran, Iran.

${ }^{7}$ Faculty of Medicine, Birjand University of Medical Sciences, Birjand, Iran.

${ }^{8}$ Department of Neuroscience, Faculty of Advanced Technologies in Medicine, Iran University of Medical Sciences, Tehran, Iran.

"Corresponding Authors:

First Corresponding Author: Faezeh Faghihi; faezefaghihi@yahoo.com, faghihi.f@iums.ac.ir.

Second Corresponding Author: Mohammad Taghi Joghataei; mt.joghataei@yahoo.com, joghataei.mt@iums.ac.ir

\# These people contribute to this work equally. 


\begin{abstract}
Background: Motor neuron- related disorders such as Spinal Cord Injuries and Amyotrophic Lateral Sclerosis are extremely common around the world. Many efforts have been made to use stem cells to modulate regeneration of spinal cord damages. Human umbilical cord blood mesenchymal stem cells (CB-MSCs) cover a class of cells with self-renewal feature and multilineage differentiation capacity. Retinoic acid(RA) and sonic hedgehog(Shh) are two morphogens responsible in motorneuron commitment during development. This study aims to explore the effect of Shh and RA on differentiation of CB-MSCs into motor neuron- like cells and to determine the related microRNA profile. To do that, human MSCs were isolated and then characterized using flowcytometry. The cells were induced using RA and Shh and the outcomes were assessed by immunocytochemistry, real-time- PCR, and flowcytometry. MicroRNA analysis was performed using Solexa system at three libraries, including Test 1 (with RA and Shh), Test 2 (After removing RA and Shh) and the Control.
\end{abstract}

Results: The isolated cells were spindle shape and could express MSC markers confirmed by flowcytometry. The cells could express motorneuron- related markers including Islet-1, Hb-9, SMI-32 and ChAT at the level of mRNA and protein, when treated with RA and Shh. Two weeks after induction, the expression of Neun and Islet-1 declined. The analysis of miRNA sequencing revealed a significant expression of mir-let-7b, mir-137 and mir-324-5p, which were responsible for neuron/motor neuron differentiation and suppression of neural progenitor cell proliferation. Moreover, some novel microRNAs involved in cholinergic, Jak- Stat, Hedgehog and Map kinase signaling pathways were revealed.

Conclusion: CB-MSC represents a type of cells with convenient accessibility, which can be differentiated into motor neuron- like cells in the presence of RA and Shh. We could also detect the expression of candid microRNAs responsible in motor neuron differentiation and some novel microRNAs involved in cholinergic, Jak- Stat, Hedgehog and Map kinase signaling pathways that must be functionally evaluated in further studies.

Keywords: MicroRNA, Motor neuron, Mesenchymal Stem cell, Cord blood 


\section{Background}

MicroRNAs (miRNAs) represent a group of non- coding RNAs that consists of 18-24 nucleotides regulating post-transcriptional gene expression, [1]. These regulators play a key role in stem cell self-renewal and fate determination. They define critical roles for gene regulation by degrading messenger RNAs or inhibiting gene translation [2,3].

Each miRNA has potentials to identify multiple target mRNAs [4]. Thus, the expression of a series of genes that control biological processes may be modulated by one miRNA. Their capacity for coordinating the control of gene expression, together with the broad range of expression across different types of cells, suggest their crucial role in cellular processes such as differentiation and cell proliferation during normal development $[5,6]$.

Recent investigations attempted to identify the link between miRNAs and neurogenesis. It has been shown that non- coding RNAs are vital to modulating transcriptional networks associated with neural development and function [7-10]. In the developing neural tube, the generation of motor neurons along the rostro- caudal axis is spatiotemporally orchestrated by set of morphogens such as Sonic Hedgehog (Shh) and Retinoic Acid (RA) [11]. Retinoic acid and Shh have a key role in specifying motor neurons in the central nervous system [12]. According to in-vitro studies, the administration of RA [13] and Shh [14] supports the differentiation of Wharton's jelly [15], bone marrow[16], olfactory mucosa [17] and chorion- derived [18] mesenchymal stem cells (MScs) into motor neuron-like cells. It appears that RA and Shh regulate how transcription factors are expressed, which are important to specifying motor neurons in the spinal cord, in a synergistic manner [12,13,18-20].

The molecular interactions downstream of retinoic acid and Shh signaling pathways are mostly unclear; however, it seems that posttranscriptional silencing carried out by microRNAs has a key role in the spatiotemporal regulation of neuronal specification [21]. The upregulation of 19 miRNAs during neurogenesis in mouse and human cells subsequent to retinoic acid (RA) treatment indicated that their functions might be conserved in mammalian species [22,23].

For example, miR-302 [24,25] and miR-124a [26] exhibited the opposite expression patterns in response to RA treatment at the beginning of neural differentiation [27] . Moreover, suppression of some microRNAs such as miR-17-3p by Shh, directs the differentiation of neuronal progenitors into motor neurons and decreases interneuron population [28].

In spite of many researches have been done in the field of neurogenesis, little is known about the role of miRNAs in neurogenesis process, as they have failed to portray a full dynamic profile for miRNA expression at the time of neurogenesis [6]. Moreover, despite the concerns of neuroscientists about the application of stem cells in neurogenesis, there is scant studies on how miRNAs regulate neural differentiation in stem cells. In this regard, studying on microRNA

profiles of differentiating stem cells would be beneficial to identify the potent microRNAs play roles during neurogenesis. 
The human Umbilical Cord Blood (UCB), which is a postpartum product, is recognized as a rich source of stem cells that can be used in regenerative medicine. UCB has a number of advantages over other sources of stem cell in regenerative medicine including convenient access, high amount of pluripotent cells, higher toleration across HLA barrier and slighter prevalence of graft- versushost disease (GVHD) [29,30]. Human UCBs achieve Mesenchymal Stem Cells (MSCs) using their self- renewal features [31], immunomodulatory [32] and neural differentiation capacities, are known as suitable candidates for regeneration of lost cells in the central nervous system. In this regard, this study was conducted to examine the miRNA profile of motor neuron- like cells derived from human CB-MSCs after treatment with RA and Shh.

\section{Materials and Methods}

\section{Cell Culture}

After gaining written informed consent from mothers, we gathered Human Cord Blood Mesenchymal Stem Cells (hCB-MSCs) from the umbilical vein of infants delivered by elective cesarean. The application of cells for this study was endorsed by the ethical committee of Iran University of Medical Sciences. Human CB- MSCs were isolated based on pre-defined protocols [33]. In short, we collected blood samples using a $50 \mathrm{ml}$ sterile syringe that contained $10 \mu 1$ of heparin and the results were transferred to the lab on an ice pack. 4 hours after collecting samples, red blood cells were removed by $1 \mathrm{ml}$ of $10 \%$ Hydroxyethyl starch (Fresenius, Germany). In the next step, the supernatant was gathered and diluted in phosphate buffered saline (PBS), and then supplemented with $100 \mathrm{U} / \mathrm{ml}$ penicillin, 0.2\% EDTA, 15\% fetal bovine serum (FBS; Gibco, Germany) and $0.1 \mathrm{mg} / \mathrm{ml}$ streptomycin (Sigma, USA). After being centrifuged over FicollHypaque (ratio 1:3; Germany) at a rate of $1200 \mathrm{rpm}$ for a period of $30 \mathrm{~min}$, mononuclear cells were achieved, cleansed in PBS and then cultured in $75 \mathrm{~cm}^{2}$ tissue culture flasks that contained DMEM-F12 accompanied with $100 \mu \mathrm{g} / \mathrm{ml}$ streptomycin, $10 \% \mathrm{FBS}$ and $100 \mathrm{U} / \mathrm{ml}$ penicillin (all purchased from Gibco, Germany). Flasks were placed in a dampened chamber at $37^{\circ} \mathrm{C}$ with $5 \%$ $\mathrm{CO}_{2}$. The medium was refreshed one week later. Then, at $70 \%$ confluence, new culture flasks were used to plate cells and the medium was changed every 3 days. The following experiments contained cells at passage 3 .

\section{Characterization of Human CB-MSCs}

Mesenchymal stem cells were characterized using mono-color cytofluorimetric analysis according to our previous protocol $[18,33]$. To do so, we incubated $10^{5}$ cells with $10 \%$ goat serum at a temperature of $4{ }^{\circ} \mathrm{C}$. After $1 \mathrm{~h}$, the serum was withdrawn and incubation of cells was performed by phycoerythrin (PE)-conjugated monoclonal antibodies or fluorescein isothiocyanate (FITC) against human CD34, CD45, CD44, CD73, and CD90 (all from BD bioscience; cat\#348057, cat\#347463, cat\#347943, cat\#561014, cat\#561970) at $4{ }^{\circ} \mathrm{C}$ for a period of $40 \mathrm{~min}$. The control 
consisted of isotype-matched antibodies. The expression of antigens was detected using BectonDickinson flow cytometer and data analysis was carried out by FlowJo software.

\section{Differentiation into Motor neuron- like Cells}

The hCB-MSCs were inducted into motor neuron- like cells based on protocols defined in the previous step [16,33]. In short, $1 \times 10^{5}$ cells were seeded in each 24 -well culture plate and incubated at dampened chamber overnight. In the next day, we replaced the expansion medium with the medium used prior to induction, which contained $20 \%$ fetal bovine serum, DMEM-F12, $10 \mathrm{ng} / \mathrm{ml}$ of fibroblast growth factor (Sigma, USA), 250mM of isobutylmethylxanthine, 2\% B27 (Gibco, Germany), and $100 \mathrm{mM}$ of $\beta$-mercaptoethanol. We retained the cells in a dampened chamber overnight. On the next day, they were treated with the induction medium that contained DMEMF12 with $100 \mathrm{ng} / \mathrm{ml}$ supplementation of Sonic hedgehog (Shh; R\&D, USA), $0.01 \mathrm{mM}$ of all-trans Retinoic Acid (RA; Sigma, USA), 1 and $0.2 \%$ B27 (Invitrogen, USA). After about a week, the medium was substituted with DMEM-F12, supplemented with $100 \mathrm{ng} / \mathrm{ml}$ of brain-derived neurotrophic factor (BDNF; Invitrogen, USA) and $0.2 \% \mathrm{~B} 27$ for a period of one week.

\section{Immunostaining}

Immunostaining was carried out to identify the expression of related antigens. To do so, we fixed cells in $4 \%$ paraformaldehyde after two weeks. Following the cell permeabilization by $0.2 \%$ Triton X-100 in PBS (Gibco, Germany) at room temperature, we washed cells by PBS and used $10 \%$ goat serum for their incubation at room temperature for a period of $60 \mathrm{~min}$. Later, samples were incubated with primary antibodies against human ChAT (Abcam, USA), Nestin (Chemicon, USA), SMI-32 (Abcam, USA) and Islet-1(Santacruz, USA) at $4^{\circ} \mathrm{C}$. In the next step, we washed cells with $\mathrm{PBS}$ and conducted incubation using the matching phycoerythrin (PE) or fluorescin isotiocyanate (FITC)- conjugated secondary antibodies (Sigma, USA) for a period of 45 min at 37 ${ }^{\circ} \mathrm{C}$. Finally, the nuclei stained was performed by DAPI (Sigma, USA) and a Olympus DP70 fluorescent microscope was used to observe cells [34].

\section{Flowcytometric Analysis}

The expressions of Islet-1, Nestin, ChAT and SMI-32 proteins were detected by FACS Calibur flow cytometer (BD BioSciences) 14 days after induction. The calibur flow cytometer was also employed to identify how these proteins are expressed. In this context, we defined positive expression as a fluorescence level above $95 \%$ compared to the one measured by corresponding isotype-matched control antibody. Data was analyzed by Flowjo software.

\section{RNA Extraction, Construction and Sequencing of Small RNA Libraries}

The RNA extraction kit was used to extract total RNA from $5 \times 10^{6}$ cells (SV total RNA isolation system; USA) as explained in the instructions provided by the manufacturer. Genomic DNA was withdrawn after incubation for $15 \mathrm{~min}$ at a temperature of $37^{\circ} \mathrm{C}$ using RNase-Free DNase (TaKaRa, Otsu, Japan), which was followed by an RNA Clean Purification Kit (BioTeke, Beijing, China). To assess the quality and integrity of RNAs, Agilent 2100 Bioanalyzer was utilized. After 
obtaining similar quantity of total RNA from a control and two test groups, the samples were pooled to create a small-RNA library. The purification of total RNA was conducted by the electrophoretic separation on a $15 \%$ denaturing polyacrylamide gel, followed by excision and recovery of small RNA regions (15 to 30 nucleotide bands). In the next step, we ligated a sequence of proprietary (Solexa) adapters to the 5'- and 3'-termini of these small RNAs. We converted gel purified products of ligation into DNA and the outcome was amplified by RT-PCR with 15 PCR cycles to create libraries. They were then sequenced by a Solexa sequencer at Beijing Genomics Institute (BGI), Hong Kong.

\section{Prediction of Conserved and Novel miRNAs}

Extensive raw sequences were collected from high-throughput sequencing. Following the removal of impure sequences (adaptor reads, low-quality reads, and reads that were less than 18 or more than 30 in length), we queried unique reads against non-coding RNAs such as rRNAs, tRNAs, small nucleolar RNAs (snoRNAs) and small nuclear RNAs (snRNAs) in the Rfam (http://www.sanger.ac.uk/Software/Rfam) and NCBI GenBank (http://www.ncbi.nih.gov/GenBank/) databases. The rest of unique reads were utilized as a nucleotide-nucleotide Basic Local Alignment Search Tool (BLASTn) search in the miRNA database (miRBase 20.0) to detect preserved miRNAs. A maximum of two mismatches was allowed. The Mireap software (https://sourceforge.net/projects/mireap/) was employed to detect novel miRNAs with the aim of predicting novel miRNAs from the rest of unknown sRNAs. Basic criteria were adopted to screen the potential novel miRNAs. We used Mfold (http://mfold.rna.albany.edu/?q=mfold/RNA-Folding-Form) to construct the stem-loop structures of putative pre-miRNAs. In the case that a complete stem-loop structure was formed; the sRNA sequence could be landed at a stem arm together with other ensuing criteria. Thus, this sRNA was considered as a new miRNA.

\section{miRNA Target Genes Prediction and Functional Annotation}

The miRanda program was adopted to predict target genes of miRNAs. Candidate targets consisted of BLASTn hits that had less than four mismatches. To predict the functions of candidate targets by BLASTX, the NCBI database and target sequences were utilized. The enrichment analysis of gene ontology (GO) (http://www.geneontology.org/) was employed for functional annotation of candidate target gene of miRNAs. To detect remarkably enriched signal transduction or metabolic pathways in target gene candidates and compare them with the whole reference gene background, we employed Kyoto Encyclopedia of Gene and Genome (KEGG) pathway database (http://www.kegg.jp/kegg/). The pathway analysis shed further light on biological functions of target genes.

\section{Pattern of Expression and Cluster Analysis}


We analyzed the reads of conserved and novel miRNAs derived from the three libraries to understand the responsive miRNAs in test groups. We computed the normalized read count using the formula below:

Normalized read count $=($ actual miRNA count of reads $/$ total count of clean reads $) \times 1000000$

Moreover, we calculated the expression fold-change by the formula below:

Fold change $=\log 2(\mathrm{~A} / \mathrm{B})$

Where A and B represent the normalized read count of a miRNA in A and B libraries.

We used the following formula to compute the $P$ value:

$$
\begin{aligned}
& p(x \mid y)=\left(\frac{N_{2}}{N_{1}}\right) \frac{(x+y) !}{x ! y !\left(1+\frac{N_{2}}{N_{1}}\right)(x+y+1)} \\
& C\left(y \leq y_{\min } \mid x\right)=\sum_{y=0}^{y \leq y_{\min }} p(y \mid x) \\
& D\left(y \geq y_{\max } \mid x\right)=\sum_{y \geq y_{\max }}^{\alpha} p(y \mid x)
\end{aligned}
$$

In the case that miRNA had no read in the library, the normalized read count of this miRNA was randomly set at 0.01 for more computations. when the expression level of a miRNA was below 20 reads, the difference analysis was abandoned. The hierarchical cluster analysis was conducted by CLUSTER 3.0 (http://rana.lbl.gov/EisenSoftware.htm) and the TREEVIEW software.

\section{miRNA Verification by Q-RT PCR}

The real-time PCR was conducted to assess the expression of some novel and conserved miRNAs that were randomly selected. We extracted total RNA from control and test groups by the RNA extraction kit (SV total RNA isolation system; USA). We removed Genomic DNA after incubation for 15 min at a temperature of $37^{\circ} \mathrm{C}$ with RNase-Free DNase (TaKaRa, Otsu, Japan), which was later followed by an RNA Clean Purification Kit (BioTeke, Beijing, China). The reverse transcription and qPCR reactions were performed by DNase-treated RNA samples. With a total volume of $20 \mu \mathrm{L}$, the reactions contained $0.8 \mu \mathrm{L}$ of each primer, $2.0 \mu \mathrm{L}$ of diluted cDNA and 10 $\mu \mathrm{L}$ of SYBR Green Mix with this cycling profile: at $95^{\circ} \mathrm{C}$ for $30 \mathrm{~s}$; accompanied with 40 cycles at $95^{\circ} \mathrm{C}$ for $5 \mathrm{~s}, 60^{\circ} \mathrm{C}$ for $20 \mathrm{~s}$. The specific amplification was verified by melting curve analysis (61 
cycles at $65^{\circ} \mathrm{C}$ for $10 \mathrm{~s}$ ). QRT-PCR was performed in 7500 real-time PCR system (Applied Biosystems, USA). A triplicate processing of each sample was conducted and 5S rRNA was adopted as an internal control. The qRT-PCR primers are depicted in Table 1.

\section{Results}

\section{Isolation of Mesenchymal Stem Cells (MSCs) from Human Cord Blood (CB)}

The isolated MSCs taken from human cord blood had spindle-like morphology throughout subsequent subcultures at passage three (Figure 1a). These cells were able to express CD44, CD73, and CD90 markers on their surfaces, but they could not express hematopoietic antigens; such as CD45 and CD34 (Figure 1b).

\section{Expression of Motor Neuron- related Markers}

CB-MSCs treated with RA and Shh expressed motor neuron- related markers including Islet- 1 and ChAT. A slight expression of SMI-32 was also detected after immunocytochemical staining (Figure 2a). Cytofluorimetric analyses suggested that after inducing cells with RA and Shh, they could express Islet-1 $(20.66 \pm 1.03 \%)$, ChAT $(42.33 \pm 2.41 \%)$ and SMI-32 (15.8 $\pm 3.26 \%)$ remarkably (Figure 2b).

\section{Deep Sequencing of Small RNA Libraries}

Using HiSeq 2500 (Illumina's sequencing platform), which is the next-generation sequencing technology, a total of 36202750 reads were achieved from the three sRNA libraries (Table 2). After filtering adaptors, low-quantity reads and poly(A) $<18$ or $>30$ in length, 33714015 reads remained, which were grouped in accordance with their redundancy in order to detect unique (nonredundant) sequences. The results showed that over 50\% of sequences were 20 to $24 \mathrm{nt}$ in length (Figure 3). Compared to other sequences in three libraries, the 22-nt and 23-nt sRNAs were significantly larger. The control and treatment groups had similar length distributions of small RNAs. The total number of sRNA reads derived from all three source libraries were identical, ranging from 12019568 (Test 1) to 11138629 (Control). It indicates that the indexed sequencing strategy had failed to generate a significant bias in source libraries.

In all libraries, unannotated sRNAs, rRNAs, miRNAs and tRNAs have most of the reads in total small RNAs (Table 3); while in unique small RNA sequences, unannotated sRNAs, rRNAs, exonsense RNAs and tRNAs are the most abundant reads in all three libraries.

The small RNAs were also divided into various categories by conducting BLAST search against Rfam. Noncoding RNAs; including unannotated RNAs, rRNAs and tRNAs were the most copious total and unique small RNAs, respectively. Categories of small RNAs were similar in our three investigated libraries. In addition, analyzing the first nucleotide (which was 18-23 nt long) sRNAs suggested that most sRNAs, especially 20 and 22, started with uridine (U) at their 5'-ends (Figure 4).

\section{Identification of Conserved miRNAs}


The majority of conserved miRNAs were associated with 22-nt and 23-nt sequences. The 21-nt, and 24-nt miRNAs were detected in several conserved miRNA families, though they were in general less frequent than the 22-nt and 23-nt miRNAs. In order to detect conserved miRNAs in Control, Test 1 and Test 2 libraries, we searched all unique sRNA sequences by aligning them against the known miRNA database in miRBase 21. A total number of 770, 749 and 659 microRNAs were found in Control, Test 1 and Test 2 libraries, respectively. From these miRNAs, 127, 126 and 112 unique miRNAs were detected in each group, respectively(Supplementary Data 1). Some miRNAs demonstrated extremely low expression levels at the libraries with an actual read count of less than 10 (i.e. hsa-miR-98-3p, hsa-miR-200b-5p and hsa-miR-150-5p, etc.). These low-expression miRNAs were not used for further expression analysis. The read counts were different in 328 known miRNAs. The miRNAs in the three libraries belonged to 56 conserved families. Overall, 466, 452 and 400 miRNA families were identified in Control, Test1 and Test2, respectively (Supplementary Data 2). Several families such as hsa-let-7, hsa-miR-21and hsamiR-30, were relatively abundant, whereas other families were less frequent. In total, 75, 60 and 26 miRNA families were only detected in Control, Test 1 and Test 2, respectively (Figure 5). Moreover, 317 families were common in all of these three libraries, while 336 miRNA families were common between Test 1 and Test 2 groups. The miRNAs length and the distributions of nucleotide preference were exhibited in Figure 4. Most miRNAs usually started with $5^{\prime}$-U and not with 5'-G, which is in agreement with common mammalian miRNA sequence patterns.

\section{Identification of Novel miRNAs}

In order to detect new miRNA sequences, we searched all unannotated small RNAs against human genome sequence. For this purpose, strict criteria were used to detect the potential new miRNA loci by the mRDeep program. It was possible to fold all precursors of the predicted new miRNAs in step-loop structures. After eliminating low-expression miRNAs (with an actual count of reads $<10$ ), we were able to predict a total of 77 potential novel miRNAs in the three libraries (Table 4). Of this figure, 13, 24 and 27 unique sequences were identified as novel miRNAs in the Control, Test 1 and Test 2 libraries, respectively. The novel miRNA sequences were 20 to $23 \mathrm{nt}$ in length. The most abundant sequence was $21 \mathrm{nt}$ reads.

\section{Prediction and Annotation of miRNA Target Genes}

We predicted the putative targets of the conserved and novel miRNAs by the miRanda program and then the functions of conserved and novel miRNAs were predicted. In order to evaluate possible functions of miRNA target genes, we carried out GO analysis. The miRNAs targets detected here were predicted based on human genome sequence. A great number of target positions were predicted for known conserved miRNAs in the sequencing libraries. A total of 621, 624 and 562 potential target genes for conserved miRNAs and 16, 39 and 38 potential target genes for novel miRNAs were identified in Control, Test 1 and Test 2 groups, respectively (Table 5). The number of miRNAs with different expressions and their targets are also listed in Table 6. The predicted targets of the conserved and novel miRNAs were included in cellular component, biological process, and molecular function. Many miRNAs had more than one predicted target 
site. Target genes of conserved and novel miRNAs were categorized in 23, 17 and 14 classes as cellular component, biological process, and molecular function, respectively. The most overrepresented GO terms in the biological process were cellular process, single-organism process and metabolic process, respectively. Moreover, in the cellular component, the most over-expressed GO terms were in cell, cell part and organelle classes. Binding and catalytic activities were classes in which most miRNAs were represented in molecular function superclass (Figure 6, Supplementary Data 3). The KEGG pathway analysis was also conducted to explore biological interpretation of the target genes. Total of 308 different pathways for conserved and novel miRNA target genes were found, among which six pathways including cholinergic synapse, hedgehog, JAK-STAT, axon guidance, TGF-beta and MAPK signaling pathways were selected as model signaling pathways (Supplementary Data 4). They played a role in motor neuron differentiation in human development. The most abundant target genes annotated with 6 selected pathways, which were differentially expressed in Control vs. Test 1, Control vs. Test 2 and Test 1 vs. Test 2 groups are listed in Table 7.

\section{Differential Expression of miRNAs in Different Libraries}

In order to find the differentially regulated miRNAs in Control, Test 1 and Test 2 groups, the reads of known and novel miRNA sequences were compared in the three libraries. Drawing on the number of reads counted by high-throughput sequencing, we compared the expression levels of conserved (Figure 7A) and new (Figure 7B) miRNAs in these libraries. The number of certain miRNAs was significantly different between the three libraries( Supplementary Data 5).

Overall, 111, 128, and 239 conserved miRNAs had different expressions in Control vs. Test 1, Control vs. Test 2 and Test 1 vs. Test 2, respectively. A comparison of miRNA expression profile in Test 1 with control showed that 10 miRNAs were downregulated. For example, hsa- miR449c-5p and hsa-miRNA- 1249- 3p were upregulated, whereas hsa- miR-335- 3p and hsa-miR335-5p were downregulated significantly.

When the miRNA expression profile in Test 2 was compared with Control, the data showed that numbers of 106 miRNAs were downregulated. For example, hsa- miR-149-3p, hsa-miR-3940$3 p$ and hsa-miRNA- 6511- 5p were downregulated, whereas hsa-miR-619-5p and hsa- miR-3687 were upregulated significantly. A comparison of the expression profile of Test 1 group with Test 2 revealed that 230 miRNAs was downregulated and 9 miRNAs such as hsa- miR-612, hsa-miR4683 and hsa-miR-3687 was upregulated.

Overall, 32, 35, and 41 novel miRNAs had different expressions in Control vs. Test 1, Control vs. Test 2 and Test 1 vs. Test 2, respectively. A comparison of miRNA expression profile in Test 1 with control showed that 27 miRNAs were upregulated. For example, novel- mir- 17, 18 and 20 were upregulated, whereas novel-mir-1 and novel-mir-2 were downregulated significantly.

A comparison of miRNA expression profile in Test 2 with Control suggested that 30 miRNAs was upregulated. For example, novel-mir-2, 3 and 6 were downregulated, whereas novel- mir- 18, 19 and 20 were upregulated significantly. 
By comparing the expression profile of Test1 group with Test 2, it was revealed that number of 21 miRNAs was downregulated; while 20 others were upregulated. MiRNAs such as novel-mir-1, novel-mir-52 and novel-mir-53 were upregulated.

\section{Q-PCR Analysis of miRNA Expression Following Induction}

The expression levels of 6 conserved miRNAs and 6 new miRNAs in Control, Test 1 and Test 2 groups were validated and measured by Q-PCR technique. We identified all randomly chosen miRNAs in Control and/or Test 1 and/or Test 2 groups by high-throughput sequencing. According to the Q-PCR analysis, all tested miRNAs were identified in the groups (Figure 8). These miRNAs had varying expression levels. The results of our qRT-PCR analysis suggested that the expression levels of new miRNAs were different from the control and the test groups. These novel miRNAs were found to have $\mathrm{Ct}$ value ranging from $34.65 \pm 1.68$ to $74.56 \pm 3.24$. To verify and measure the differential expression levels of miRNAs, the qRT-PCR analysis was undertaken. The proposed known and novel miRNAs exhibited both significant and insignificant expression differences in the three libraries. Our qRT-PCR results suggested that hsa- mir- let7i-5p, hsa- mir- 146a-5p, hsamir- 328-3p hsa- mir- 663a-5p, novel-mir-1, novel-mir-4 and novel-mir-17 as well as novel-mir53 revealed expression patterns comparable to those illustrated by our high-throughput sequencing analysis. The expression levels of hsa-mir-432-5p, hsa-mir-335-3p, novel-mir-2 and novel-mir-21 differed from our sequencing outcomes as a result of sequencing error or other unknown reasons.

\section{Discussion}

MicroRNAs have been known to be the most important regulatory molecule involved in neurogenesis. Despite the bulk of studies that suggest the inhibition of microRNA biogenesis results in inappropriate neurulation, the biology of miRNAs during neuronal differentiation is poorly understood. Little is known about the role of miRNAs in the process of motor neuron development. The previous studies have failed to capture the full dynamic profile of miRNA expression during neurogenesis. In this regard, this study was undertaken to examine the miRNA profile of differentiating human umbilical cord blood mesenchymal stem cells (hUCB-MSCs) during differentiation into motor neuron- like cells using retinoic acid and sonic hedgehog via a three- step protocol. At phase I, cells were induced with isobutylmethylxanthine and $\beta$ mercaptoethanol. At phase II, RA and Shh were used synergistically to mimic the development of neural tube roastrocaudally (by RA) and dorso- ventrally (by Shh). At phase III, the differentiating cells were induced by neurotrophic factors such as BDNF [35-37].

According to the results, we were able to detect the expression of neural and motor neuron related markers, such as Islet-1, Nestin, Pax-6, Hb-9, and ChAT along with SMI-32 using real-time PCR 7 and 14 days after induction compared with non- treated mesenchymal stem cells. We also managed to detect the expression of Nestin, SMI-32, Islet-1 and ChAT at the level of protein using immunocytochemistry and flowcytometry. To investigate the miRNA profile of differentiating cells, three small RNA libraries were provided from the following groups: Test 1 (cells at the onset 
of induction with RA and Shh), Test 2 (cells after induction with RA and Shh and at the onset of induction with BDNF) and the Control (non- treated mesenchymal stem cells).

The relationship between microRNAs and neurogenesis has been shown extensively in the literature. Non- coding RNAs play a prominent role in regulation of transcription networks in the development of neural system. About 500 miRNA genes with various target mRNAs have been identified in humans and mice. Recognition of these miRNAs will shed further light on neurogenesis.

In the present study, we were able to detect the expression of hsa-mir-9-5p after induction with RA and Shh (Test 1). However, the expression of this miRNA dropped significantly at Test 2. Mir9 was known to be a highly conserved miRNA in the central nervous system. This miRNA regulates the normal development of the brain [38]. Mir-9-3p and mir-9-5p are involved in normal development of the central nervous system by striking a balance between differentiation and selfrenewal of neural stem cells[39]. Mir-9 affects the expression of TLX in neural stem cells [40]. The expression of TLX is constrained during differentiation of neural stem cells while the expression of mir-9 increases at the same time. On the other hand, by regulating the expression of Onecut transcription factor, mir-9 controls the differentiation of early motor neurons into mature motor neurons. Moreover, Onecut supports the expression of Islet-1 and LMCms. The interaction of Islet-1 and another transcription factor, Lhx1, supports the formation of lateral LMCs.

The development of Lhx 1p LMC depends on retinoic acid secreted from LMCms [41]. Regulatory networks in the downstream of retinoic acid and the upstream of Islet-1/Lhx1 are currently unknown. FoxP1 is another transcription factor involved in preganglionic and lateral motor neurons. Mir-9 controls motor neuron formation by regulating the level of FoxP1 expression [42].

Our results also showed a significant upregulation of mir-let7b in Test 1 and Test 2 groups in comparison with the Control. The upregulation of mir- let7b suppresses the proliferation of neural stem cells and induces neural differentiation. This microRNA targets TLX, a nuclear receptor and its effector cyclinD1, to control the proliferation and differentiation of neural stem cells. In the brain of old adults, mir- let7b reduces the self-renewal properties of neural progenitor cells [43] cells into neurons or glial cells by regulating the expression of HMGA2 and HES5 in the notch signaling pathway.

We could also identify the upregulation of mir-324-5p in Test 1 group in the presence of Shh as an inducing factor. This miRNA target Gli-1 as a member of Shh signaling pathway [44].

Our results showed a significant upregulation in the expression mir-137 in Test 2 group when cells were treated with BDNF. According to previous reports, mir- 137 regulates the maturation of neurons. The upregulation of this miRNA suppresses the morphogenesis of dendrites, cellular phenotypes, and the development of spinal cord and early neural cells. Mir-137 regulates the expression of an ubiquitin ligase called Mind Bomb-1[45]. It also targets H3K27 in Ezh2 methyltransferase to control the proliferation and differentiation of neural progenitor cells in adults. It seems that mir- 137 is involved in regulating the maturation of neurogenesis in 
hippocampus. We also managed to detect the expression of mir-132 in Test 2. This miRNA is expressed in neurons but not in astrocytes or neural progenitor cells. Similar to mir- 137, mir- 132 is prevalent in dendrites. Unlike Mir- 137, mir- 132 reduces the volume of the spine [46].

In this study, some novel microRNAs were detected exclusively in one group or shared between other groups. For example, mirs-3, 8, 13 were expressed in the Control, Test 1 and Test 2, respectively. Eight miRNAs were common only in Test 1 and Test 2 groups.

We also investigated four candid signaling pathways involved in neurogenesis including acetylcholine signaling pathway, hedgehog signaling pathways, Jak-Stat signaling pathway and MAP kinase pathway. The results showed the expression of miRNAs involved in acetylcholine pathway after neural induction in Test 1 and Test 2 groups compared with the Control. Novel miRNAs related to Hh signaling pathway were upregulated in Test 1 group when compared with Test 2 group, probably due to the presence of Shh in the induction medium of Test 1 group.

In Jak-STAT signaling pathway, some novel miRNAs were upregulated in Test 2 group when the results were compared with the Control and Test 1 group.

In MAP kinase pathway, some novel miRNAs were found in test groups when compared with non- treated mesenchymal stem cells.

\section{Conclusions}

Our results suggested that CB-MSCs are potent enough to express motor neuron-related markers at m- RNA level and proteins in the presence of sonic hedgehog and retinoic acid. On the other hand, the analysis of miRNA profile of these motor neuron- like cells showed a significant upregulation in the expression of mir-9, mir-let7b, mir-137 and mir-324-5p, which are involved in neural differentiation and neuron/motor neuron maturation. Moreover, some novel microRNAs involved in cholinergic, hedgehog, MAP kinase and JAK-STAT signaling pathways were also detected in the test groups. However, further studies are required to validate their functions in mechanisms related to motor neuron differentiation and maturation.

\section{List of Abbreviations}

hCB-MSCs: Human Cord Blood Mesenchymal Stem Cells; RA: Retinoic Acid; Shh: Sonic hedgehog; UCB: Umbilical Cord Blood;GVHD: Graft Versus Host Disease; miRNA: MicroRNA.

\section{Declarations}

\section{Ethics approval and consent to participate}

Isolation and application of Human Cord Blood Mesenchymal Stem Cells were approved by the ethical committee of Iran University of Medical Sciences (code:IR.IUMS.REC 1395.95-03-117-28604). All blood samples were used after obtaining maternal written informed consent, approved by the ethical committee of Iran University of Medical Sciences. 


\section{Consent for publication}

Not applicable.

\section{Availability of data and materials}

All data generated or analyzed during this study are included in this published article and its supplementary information files.

\section{Competing interests}

The authors declare no Competing interests.

\section{Funding}

This study was granted by Iran University of Medical Sciences (Grant No. 92-03-117-23954), Iran National Science Foundation (INSF), Iranian Council of Stem Cell Research and Technology (IR) (IRSCC; Grant No. REP-310) and Pad Nahad Tabiat (PNT), Ltd. Company.

\section{Authors' contributions}

DS contributed in cell culture, flowcytometry, ICC staining and molecular experiments. AL contributed in molecular biology studies and data analyses. AK, ZB, EL contributed in microRNA data analyses, cell culture techniques and flowcytometry as well as immunocytochemical staining. BY contributed in cell culture. FF and MTJ contributed in designing the project, data analyses, writing the results and obtaining grants.

\section{Acknowledgements}

The authors would like to thank staffs of Cellular and Molecular Research Center, Iran University of Medical Sciences for their kindness and supports.

\section{Figure legends}

Figure 1. Characterization of isolated human CB-MSCs. (a) Cells with a fibroblast-like morphology are shown (magnification 10X). (b) Cytofluorimetric analysis showed that cells could express mesenchymal stem cell markers such as CD44, CD73, and CD90, while they turned out to be negative for hematopoietic markers like CD34 and CD45.

Figure 2. CB- MSCs after differentiation into motor quasi-neuron cells using RA and Shh. (a) The cells could express motor neuron- related markers such as ChAT, SMI-32 and Islet-1. A slight expression of SMI-32 was also detected after immunocytochemical staining (a; scale bar: $50 \mu \mathrm{m}$ ). (b) Cytofluorimetric analyses revealed that $42.33 \pm 2.41 \%, 15.8 \pm 3.26 \%$ and $20.66 \pm 1.03 \%$ of cells could express ChAT, SMI-32 and Islet-1, respectively(b). 
Figure 3. The distribution of Size in sequenced small RNAs at all three libraries. CTRL: Small RNA library built from CB- MSCs under the control condition. Test 1: small RNA library derived from CB-MSCs treated with RA and Shh. Test 2: small RNA library obtained from Test1 cells treated with a surviving factor, BDNF.

Figure 4. First nucleotide bias of the conserved and novel miRNAs at the three libraries. From up to down: Control, Test1 and Test 2.

Figure 5. Identification of conserved miRNAs. Overall. 75, 60 and 26 miRNA families were only detected in Control, Test 1 and Test 2, respectively.

Figure 6. miRNA target genes prediction and annotation. Target genes of conserved (a) and novel(b) miRNAs were categorized in 23,17 and 14 classes as cellular component, biological process and molecular function, respectively. The most over-represented GO terms in the biological process were cellular process, single organism process and metabolic process. In the cellular component, however, the most over-expressed GO terms were in cell, cell part and organelle classes. Binding and catalytic activities were classes in which most of miRNAs were expressed in molecular function superclass.

Figure 7. Differential expression of miRNAs. According to the number of reads counted by high-throughput sequencing, a comparison was drawn between the expression levels of conserved (a) and new (b) miRNAs at the three libraries.

Figure 8. Q-PCR analysis of miRNA expression. Q-PCR technique was used to verify and measure the expression levels of six conserved miRNAs and six novel miRNAs in Control, Test 1 and Test 2 groups.

\section{References}

1- Cao, D.-D., Li, L., \& Chan, W.-Y. (2016). MicroRNAs: Key Regulators in the Central Nervous System and Their Implication in Neurological Diseases. International Journal of Molecular Sciences, 17(6), 842. https://doi.org/10.3390/ijms17060842

2- Ambros, V. (2004). The functions of animal microRNAs. Nature, 431(7006), 350-355. https://doi.org/10.1038/nature02871

3- Bartel, D. P. (2004). MicroRNAs: Genomics, Biogenesis, Mechanism, and Function. Cell, 116(2), 281297. https://doi.org/10.1016/S0092-8674(04)00045-5 
4- Lim, L., Lau, N., Garrett-Engele, P., \& -, A. G. (2005). Microarray analysis shows that some microRNAs downregulate large numbers of target mRNAs. Nature, 433, 769-733. https://doi.org/10.1038/nature03315

5- Visvanathan, J., Lee, S., Lee, B., \& Lee, S.-K. (2008). MIR-124 antagonizes the anti-neural rest/scp1 pathway during embryonic development. Developmental Biology, 319(2), 574. https://doi.org/10.1016/j.ydbio.2008.05.380

6- Smith, B., Treadwell, J., Zhang, D., Ly, D., McKinnell, I., Walker, P. R., \& Sikorska, M. (2010). LargeScale Expression Analysis Reveals Distinct MicroRNA Profiles at Different Stages of Human Neurodevelopment. PLoS ONE, 5(6), e11109. https://doi.org/10.1371/journal.pone.0011109

7- Kosik, K. S., \& Krichevsky, A. M. (2005). The elegance of the microRNAs: A neuronal perspective. Neuron, Vol. 47, pp. 779-782. https://doi.org/10.1016/j.neuron.2005.08.019

8- Cao, X., Yeo, G., Muotri, A. R., Kuwabara, T., \& Gage, F. H. (2006). NONCODING RNAS IN THE MAMMALIAN CENTRAL NERVOUS SYSTEM. Annual Review of Neuroscience, 29(1), 77-103. https://doi.org/10.1146/annurev.neuro.29.051605.112839

9- Mehler, M. F., \& Mattick, J. S. (2007). Noncoding RNAs and RNA Editing in Brain Development, Functional Diversification, and Neurological Disease. Physiological Reviews, 87(3), 799-823. https://doi.org/10.1152/physrev.00036.2006

10- Haramati, S., Chapnik, E., Sztainberg, Y., Eilam, R., Zwang, R., Gershoni, N., ... Hornstein, E. (2010). miRNA malfunction causes spinal motor neuron disease. Proceedings of the National Academy of Sciences, 107(29), 13111-13116. https://doi.org/10.1073/pnas.1006151107

11- Luxenhofer, G., Helmbrecht, M. S., Langhoff, J., Giusti, S. A., Refojo, D., \& Huber, A. B. (2014). MicroRNA-9 promotes the switch from early-born to late-born motor neuron populations by regulating Onecut transcription factor expression. Developmental Biology, 386(2), 358-370. https://doi.org/10.1016/j.ydbio.2013.12.023

12- Maden, M. (2002). REtinoid Signalling in the Nervous System. Neuroscience, 3(11):843-53.. https://doi.org/10.1038/nrn963

13- Novitch, B. G., Wichterle, H., Jessell, T. M., \& Sockanathan, S. (2003). A requirement for retinoic acid-mediated transcriptional activation in ventral neural patterning and motor neuron specification. J Neuron. 40(1), 81-95. https://doi.org/10.1016/j.neuron.2003.08.006

14- Briscoe, J., Chen, Y., Jessell, T. M., \& Struhl, G. (2001). A hedgehog-insensitive form of Patched 
provides evidence for direct long-range morphogen activity of Sonic hedgehog in the neural tube. Molecular Cell, 7(6), 1279-1291. https://doi.org/10.1016/S1097-2765(01)00271-4

15- Bagher, Z., Ebrahimi-Barough, S., Azami, M., Mirzadeh, H., Soleimani, M., Ai, J., ... Joghataei, M. T. (2015). Induction of human umbilical Wharton's jelly-derived mesenchymal stem cells toward motor neuron-like cells. In Vitro Cellular and Developmental Biology - Animal. https://doi.org/10.1007/s11626-015-9921-z

16- Faghihi, F., Mirzaei, E., Sarveazad, A., Ai, J., Ebrahimi Barough, S., Lotfi, A., \& Joghataei, M. T. (2015). Differentiation Potential of Human Bone Marrow Mesenchymal Stem Cells into Motorneuron-like Cells on Electrospun Gelatin Membrane. Journal of Molecular Neuroscience, 55(4), 845-853. https://doi.org/10.1007/s12031-014-0437-x

17- Bagher, Z., Kamrava, S. K., Alizadeh, R., Farhadi, M., Absalan, M., Falah, M., ... Komeili, A. (2018). Differentiation of neural crest stem cells from nasal mucosa into motor neuron-like cells. Journal of Chemical Neuroanatomy, 92, 35-40. https://doi.org/10.1016/j.jchemneu.2018.05.003

18- Faghihi, F., Mirzaei, E., Ai, J., Lotfi, A., Sayahpour, F. A., Barough, S. E., \& Joghataei, M. T. (2016). Differentiation Potential of Human Chorion-Derived Mesenchymal Stem Cells into Motor NeuronLike Cells in Two- and Three-Dimensional Culture Systems. Molecular Neurobiology, 53(3), 18621872. https://doi.org/10.1007/s12035-015-9129-y

19- Ericson, J., Rashbass, P., Schedl, A., Brenner-Morton, S., Kawakami, A., Van Heyningen, V., ... Briscoe, J. (1997). Pax6 controls progenitor cell identity and neuronal fate in response to graded Shh signaling. Cell, 90(1), 169-180. https://doi.org/10.1016/S0092-8674(00)80323-2

20- Sockanathan, Shanthini, \& Jessell, T. M. (1998). Motor neuron-derived retinoid signaling specifies the subtype identity of spinal motor neurons. Cell, 94(4), 503-514. https://doi.org/10.1016/S00928674(00)81591-3

21- Shi, Y., Zhao, X., Hsieh, J., Wichterle, H., Impey, S., Banerjee, S., ... Kosik, K. S. (2010). MicroRNA regulation of neural stem cells and neurogenesis. The Journal of Neuroscience : The Official Journal of the Society for Neuroscience, 30(45), 14931-14936. https://doi.org/10.1523/JNEUROSCI.428010.2010

22- Hohjoh, H., \& Fukushima, T. (2007). Marked change in microRNA expression during neuronal differentiation of human teratocarcinoma NTera2D1 and mouse embryonal carcinoma P19 cells. Biochemical and Biophysical Research Communications, 362(2), 360-367. https://doi.org/10.1016/j.bbrc.2007.07.189 
23- Sempere, L. F., Freemantle, S., Pitha-Rowe, I., Moss, E., Dmitrovsky, E., \& Ambros, V. (2004). Expression profiling of mammalian microRNAs uncovers a subset of brain-expressed microRNAs with possible roles in murine and human neuronal differentiation. Genome Biology, 5(3), R13. https://doi.org/10.1186/gb-2004-5-3-r13

24- Houbaviy, H. B., Murray, M. F., \& Sharp, P. A. (2003). Embryonic stem cell-specific microRNAs. Developmental Cell, 5(2), 351-358. https://doi.org/10.1016/S1534-5807(03)00227-2

25- Suh, M. R., Lee, Y., Kim, J. Y., Kim, S. K., Moon, S. H., Lee, J. Y., ... Kim, K. S. (2004). Human embryonic stem cells express a unique set of microRNAs. Developmental Biology, 270(2), 488-498. https://doi.org/10.1016/j.ydbio.2004.02.019

26- Krichevsky, A. M., Sonntag, K.-C., Isacson, O., \& Kosik, K. S. (2006). Specific MicroRNAs Modulate Embryonic Stem Cell-Derived Neurogenesis. STEM CELLS, 24(4), 857-864. https://doi.org/10.1634/stemcells.2005-0441

27- Sim, S.-E., Lim, C.-S., Kim, J.-I., Seo, D., Chun, H., Yu, N.-K., ... Kaang, B.-K. (2016). The Brain-Enriched MicroRNA miR-9-3p Regulates Synaptic Plasticity and Memory. The Journal of Neuroscience, 36(33), 8641-8652.

28- Chen, J. A., Huang, Y. P., Mazzoni, E. O., Tan, G. C., Zavadil, J., \& Wichterle, H. (2011). Mir-17-3p Controls Spinal Neural Progenitor Patterning by Regulating Olig2/Irx3 Cross-Repressive Loop. Neuron, 69(4), 721-735. https://doi.org/10.1016/j.neuron.2011.01.014

29- Kurtzberg, J., Laughlin, M., Graham, M. L., Smith, C., Olson, J. F., Halperin, E. C., ... Rubinstein, P. (1996). Placental Blood as a Source of Hematopoietic Stem Cells for Transplantation into Unrelated Recipients. New England Journal of Medicine, 335(3), 157-166. https://doi.org/10.1056/NEJM199607183350303

30- Rubinstein, P., Carrier, C., Scaradavou, A., Kurtzberg, J., Adamson, J., Migliaccio, A. R., ... Stevens, C. E. (1998). Outcomes among 562 Recipients of Placental-Blood Transplants from Unrelated Donors. New England Journal of Medicine, 339(22), 1565-1577. https://doi.org/10.1056/NEJM199811263392201

31- Lee, M. W., Choi, J., Yang, M. S., Moon, Y. J., Park, J. S., Kim, H. C., \& Kim, Y. J. (2004). Mesenchymal stem cells from cryopreserved human umbilical cord blood. Biochemical and Biophysical Research Communications, 320(1), 273-278. https://doi.org/10.1016/j.bbrc.2004.04.206

32- Shawki, S., Gaafar, T., Erfan, H., El Khateeb, E., El Sheikhah, A., \& El Hawary, R. (2015). Immunomodulatory effects of umbilical cord-derived mesenchymal stem cells. Microbiology and 
Immunology, 59(6), 348-356. https://doi.org/10.1111/1348-0421.12259

33- Yousefi, B., Sanooghi, D., Faghihi, F., Joghataei, M. T., \& Latifi, N. (2017). Evaluation of motor neuron differentiation potential of human umbilical cord blood- derived mesenchymal stem cells, in vitro. Journal of Chemical Neuroanatomy, 81, 18-26. https://doi.org/10.1016/j.jchemneu.2017.01.003

34- Bagher, Z., Azami, M., Ebrahimi-Barough, S., Mirzadeh, H., Solouk, A., Soleimani, M., ... Joghataei, M. T. (2016). Differentiation of Wharton's Jelly-Derived Mesenchymal Stem Cells into Motor Neuron-Like Cells on Three-Dimensional Collagen-Grafted Nanofibers. Molecular Neurobiology, 53(4), 2397-2408. https://doi.org/10.1007/s12035-015-9199-х

35- Salehi, M., Bagher, Z., Kamrava, S. K., Ehterami, A., Alizadeh, R., Farhadi, M., .. Komeili, A. (2019). Alginate/chitosan hydrogel containing olfactory ectomesenchymal stem cells for sciatic nerve tissue engineering. Journal of Cellular Physiology. https://doi.org/10.1002/jcp.28183

36- Bagher, Z., Atoufi, Z., Alizadeh, R., Farhadi, M., Zarrintaj, P., Moroni, L., ... Kamrava, S. K. (2019). Conductive hydrogel based on chitosan-aniline pentamer/gelatin/agarose significantly promoted motor neuron-like cells differentiation of human olfactory ecto-mesenchymal stem cells. Materials Science and Engineering C, 101, 243-253. https://doi.org/10.1016/j.msec.2019.03.068

37- Bagher, Z., Ebrahimi-Barough, S., Azami, M., Safa, M., \& Joghataei, M. T. (2016). Cellular activity of Wharton's Jelly-derived mesenchymal stem cells on electrospun fibrous and solvent-cast film scaffolds. Journal of Biomedical Materials Research Part A, 104(1), 218-226. https://doi.org/10.1002/jbm.a.35555

38- Coolen, M., Katz, S., \& Bally-Cuif, L. (2013). miR-9: a versatile regulator of neurogenesis. Frontiers in Cellular Neuroscience, 7. https://doi.org/10.3389/fncel.2013.00220

39- Sim, S.-E., Lim, C.-S., Kim, J.-I., Seo, D., Chun, H., Yu, N.-K., ... Kaang, B.-K. (2016). The BrainEnriched MicroRNA miR-9-3p Regulates Synaptic Plasticity and Memory. The Journal of Neuroscience, 36(33), 8641-8652. https://doi.org/10.1523/JNEUROSCI.0630-16.2016

40- Zhao, C., Sun, G., Li, S., \& Shi, Y. (2009). A feedback regulatory loop involving microRNA-9 and nuclear receptor TLX in neural stem cell fate determination. Nature Structural and Molecular Biology, 16(4), 365-371. https://doi.org/10.1038/nsmb.1576

41- Schaller, S., Buttigieg, D., Alory, A., Jacquier, A., Barad, M., Merchant, M., ... Haase, G. (2017). Novel combinatorial screening identifies neurotrophic factors for selective classes of motor neurons.

42- Otaegi, G., Pollock, A., Hong, J., (2011) MicroRNA miR-9 modifies motor neuron columns by a tuning regulation of FoxP1 levels in developing spinal cords. J Neurosci 31(3):809-18. doi: 


\subsection{3/JNEUROSCI.4330-10.}

43- Patterson, M., Gaeta, X., Loo, K., Edwards, M., Smale, S., Cinkornpumin, J., ... Lowry, W. E. (2014). Let-7 miRNAs can act through NOTCH to regulate human gliogenesis. Stem Cell Reports, 3(5), $758-$ 773. https://doi.org/10.1016/j.stemcr.2014.08.015

44- Cohen, M., Kicheva, A., Ribeiro, A., Blassberg, R., Page, K. M., Barnes, C. P., \& Briscoe, J. (2015). Ptch1 and Gli regulate Shh signalling dynamics via multiple mechanisms. Nature Communications, 6. https://doi.org/10.1038/ncomms7709

45- Mahmoudi, E., \& Cairns, M. J. (2017). MiR-137: An important player in neural development and neoplastic transformation. Molecular Psychiatry, Vol. 22, pp. 44-55. https://doi.org/10.1038/mp.2016.150

46- Yang, D., Li, T., Wang, Y., Tang, Y., Cui, H., Tang, Y., Le, W. (2012). miR-132 regulates the differentiation of dopamine neurons by directly targeting Nurr1 expression. Journal of Cell Science, 125(7),16731682. 
a

b
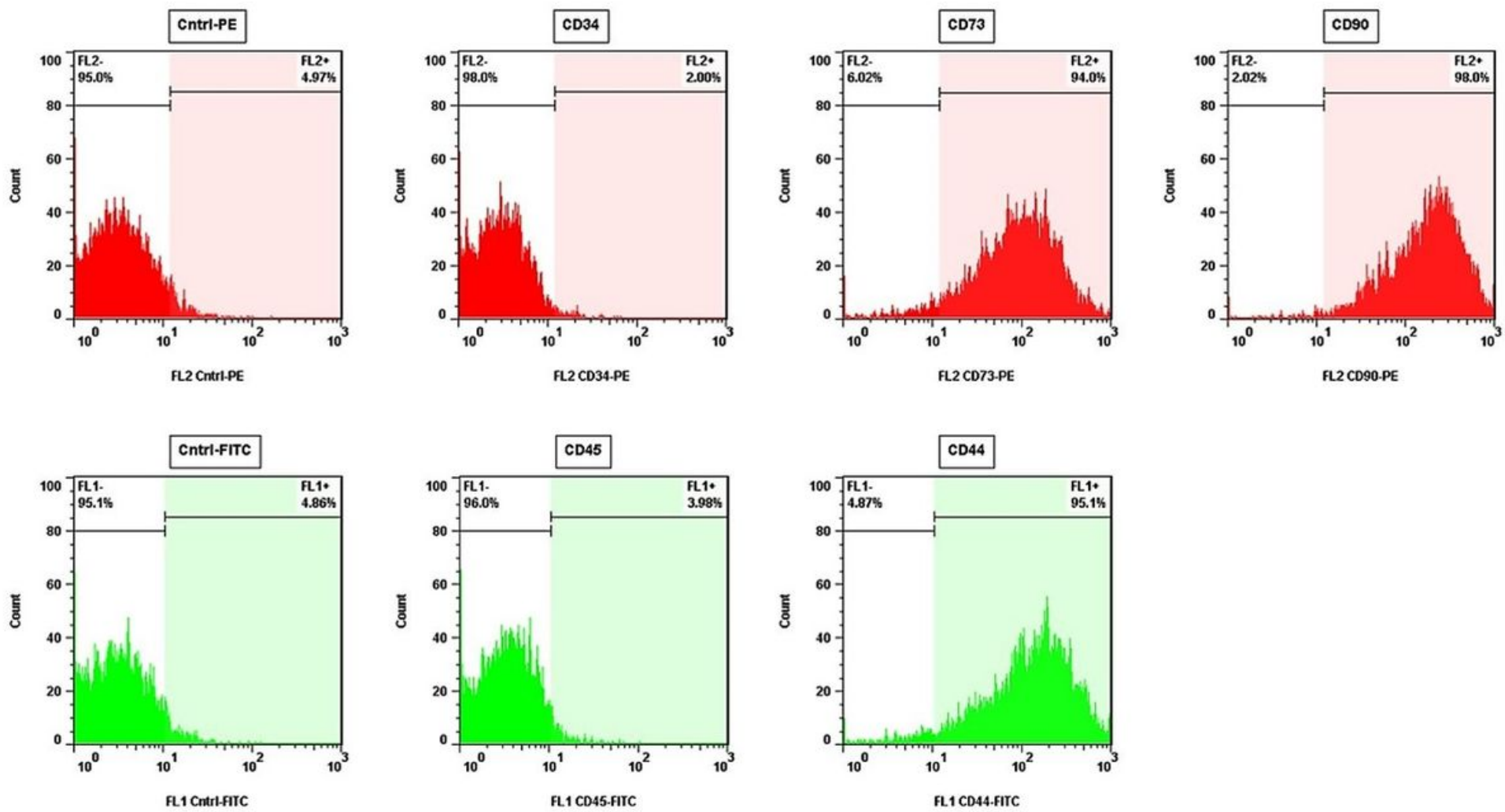

Figure 1

Characterization of isolated human CB-MSCs. (a) Cells with a fibroblast-like morphology are shown (magnification 10X). (b) Cytofluorimetric analysis showed that cells could express mesenchymal stem cell markers such as CD44, CD73, and CD90, while they turned out to be negative for hematopoietic markers like CD34 and CD45. 
a
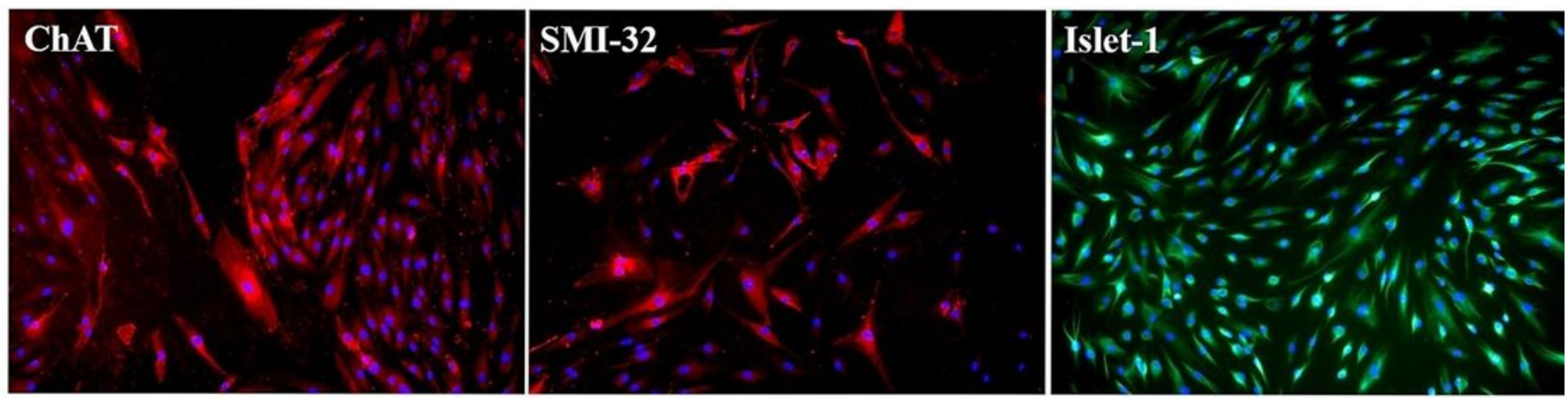

b
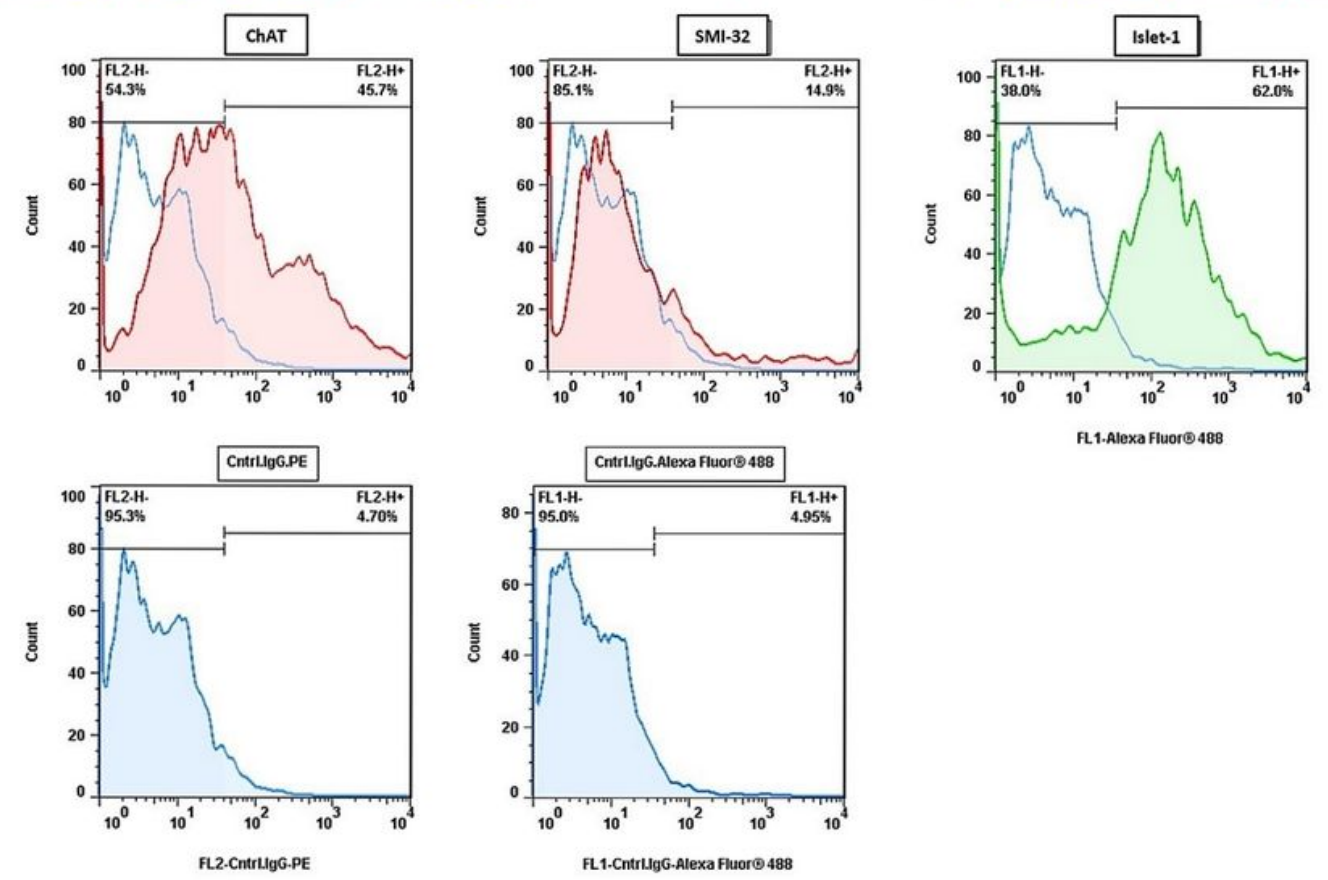

\section{Figure 2}

CB- MSCs after differentiation into motor quasi-neuron cells using RA and Shh. (a) The cells could express motor neuron- related markers such as ChAT, SMI-32 and Islet-1. A slight expression of SMI-32 was also detected after immunocytochemical staining (a; scale bar: $50 \mu \mathrm{m}$ ). (b) Cytofluorimetric analyses revealed that $42.33 \pm 2.41 \%, 15.8 \pm 3.26 \%$ and $20.66 \pm 1.03 \%$ of cells could express ChAT, SMI-32 and Islet- 1 , respectively(b). 


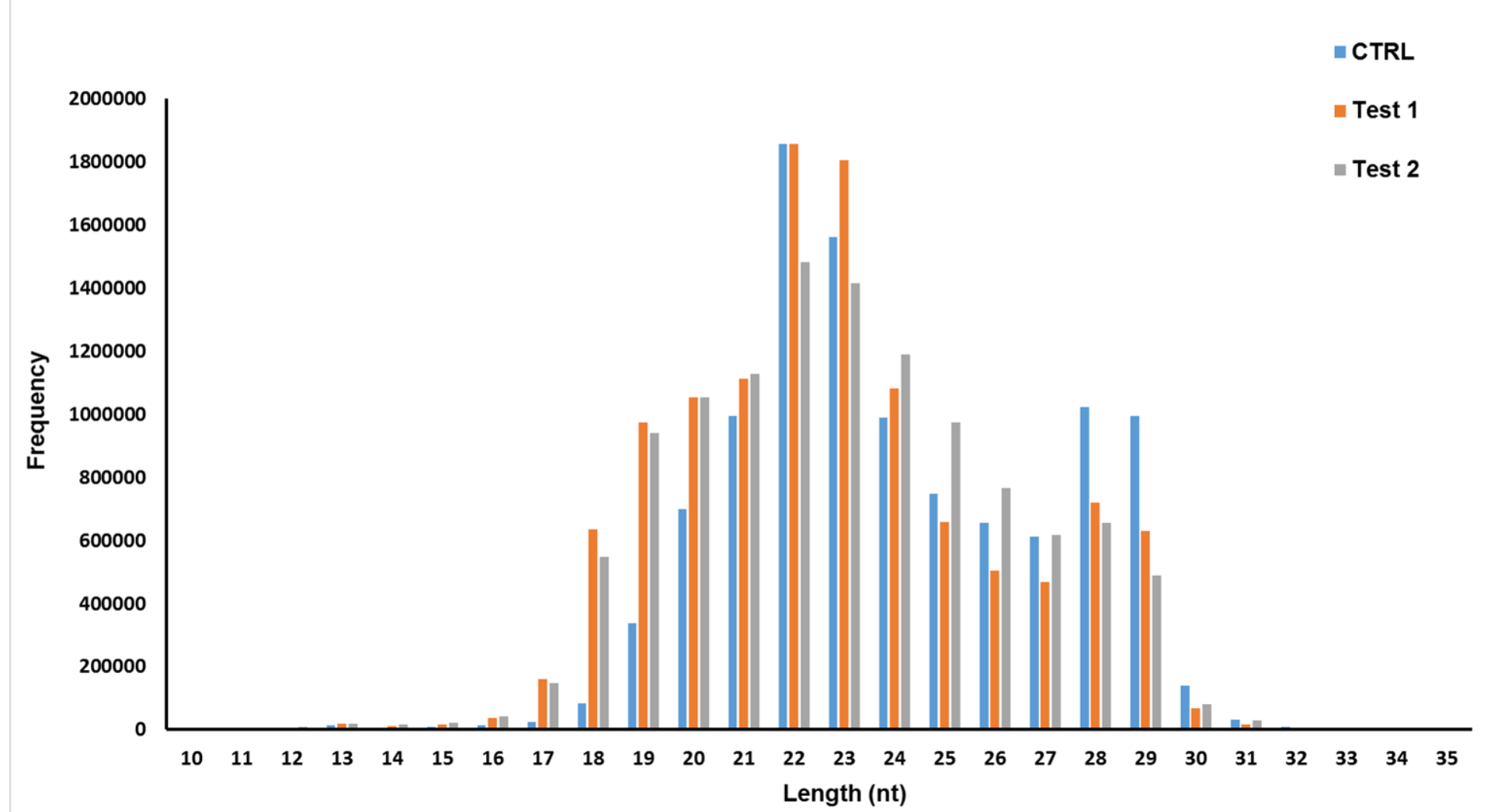

Figure 3

The distribution of Size in sequenced small RNAs at all three libraries. CTRL: Small RNA library built from CB- MSCs under the control condition. Test 1: small RNA library derived from CB-MSCs treated with RA and Shh. Test 2: small RNA library obtained from Test1 cells treated with a surviving factor, BDNF. 

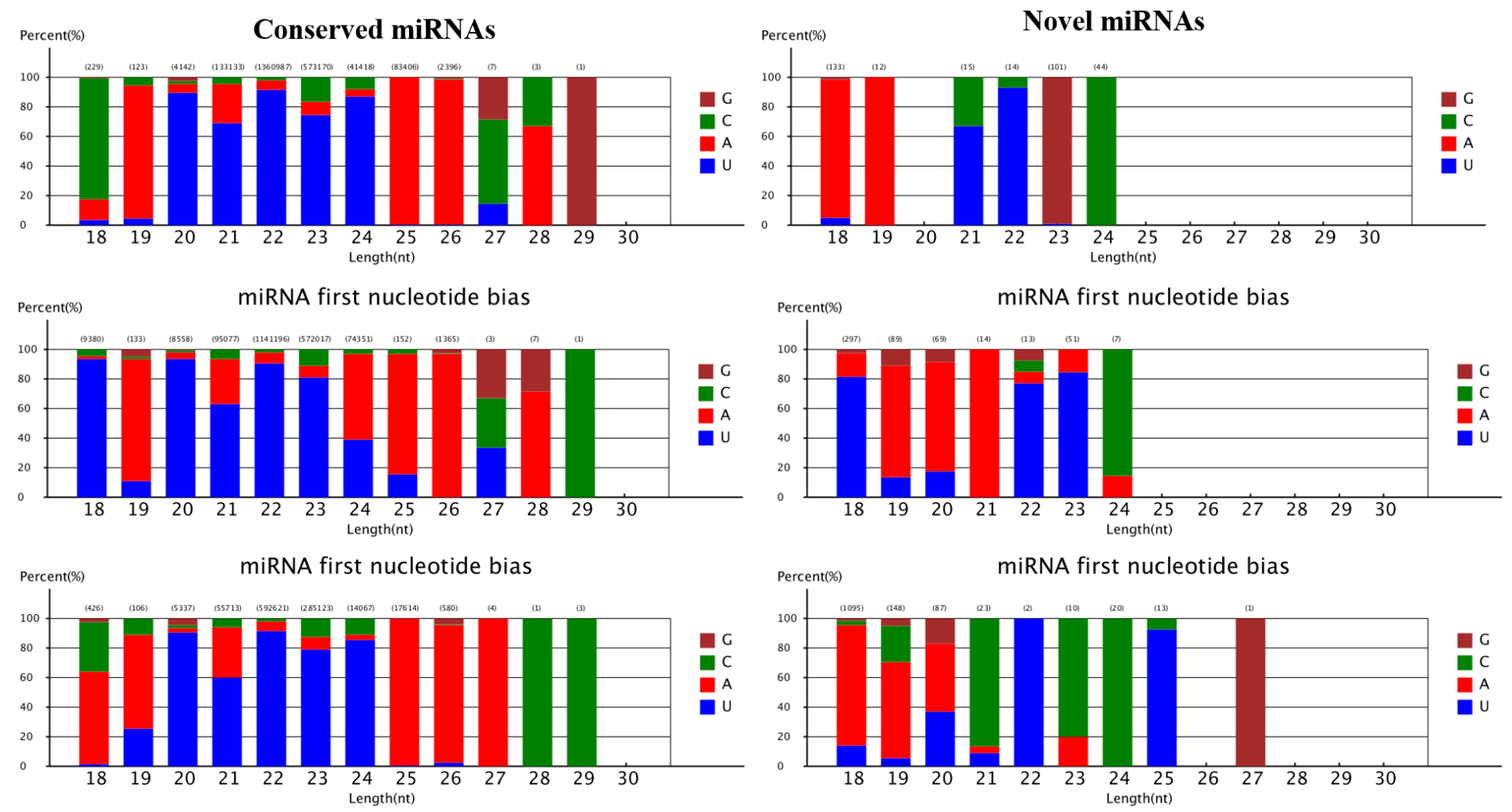

Figure 4

First nucleotide bias of the conserved and novel miRNAs at the three libraries. From up to down: Control, Test1 and Test 2. 


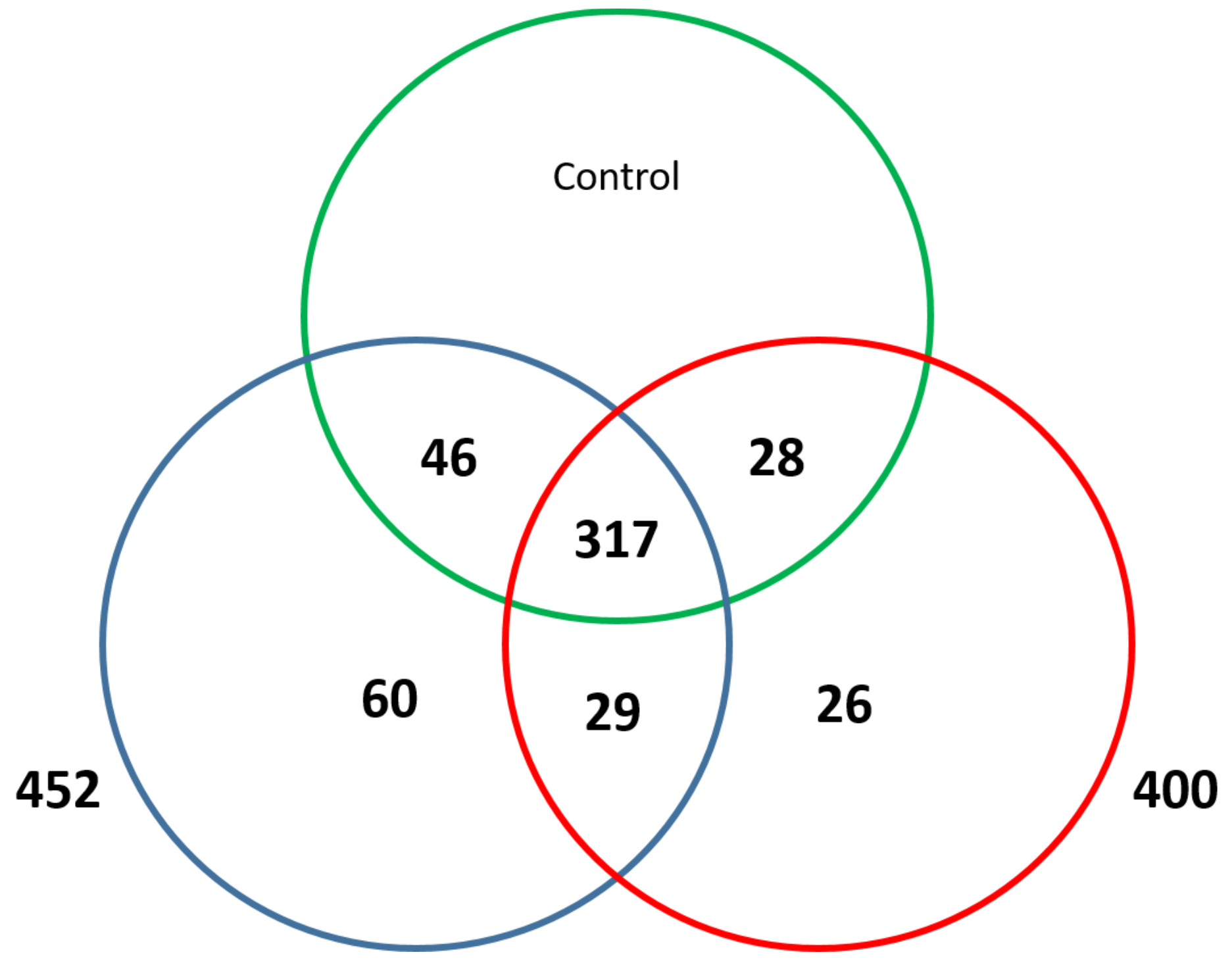

Figure 5

Identification of conserved miRNAs. Overall. 75, 60 and 26 miRNA families were only detected in Control, Test 1 and Test 2, respectively. 

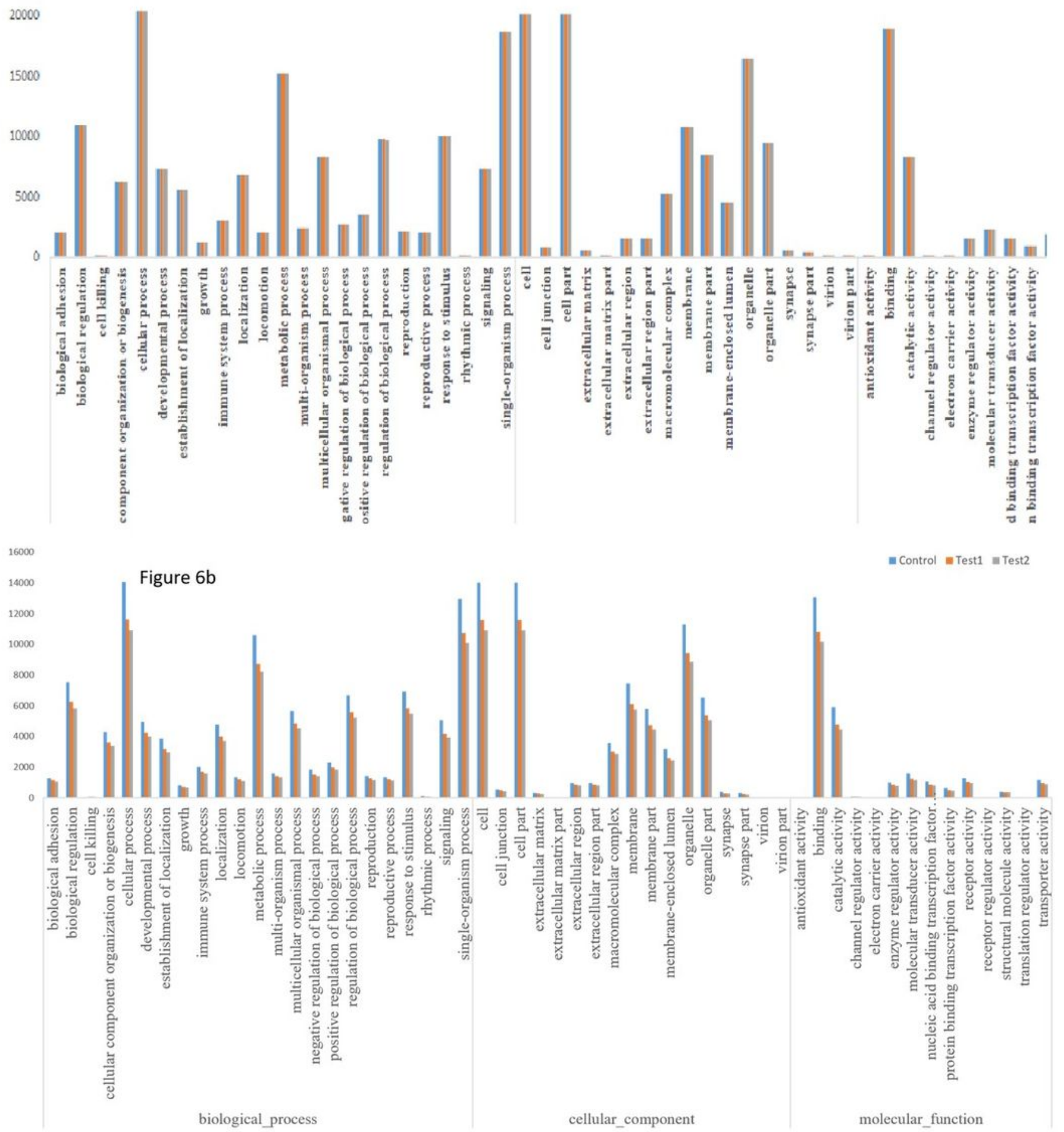

\section{Figure 6}

miRNA target genes prediction and annotation. Target genes of conserved (a) and novel(b) miRNAs were categorized in 23, 17 and 14 classes as cellular component, biological process and molecular function, respectively. The most over-represented GO terms in the biological process were cellular process, single organism process and metabolic process. In the cellular component, however, the most over-expressed 
GO terms were in cell, cell part and organelle classes. Binding and catalytic activities were classes in which most of miRNAs were expressed in molecular function superclass.

Scatter plot (control:x | treatment:y

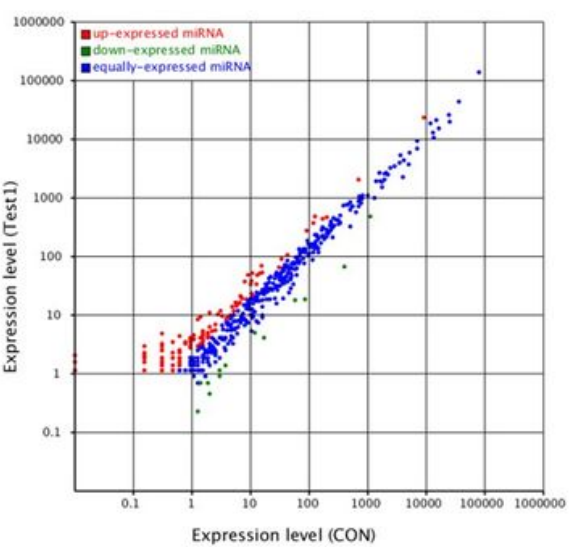

Scatter plot (control:x | treatment:y

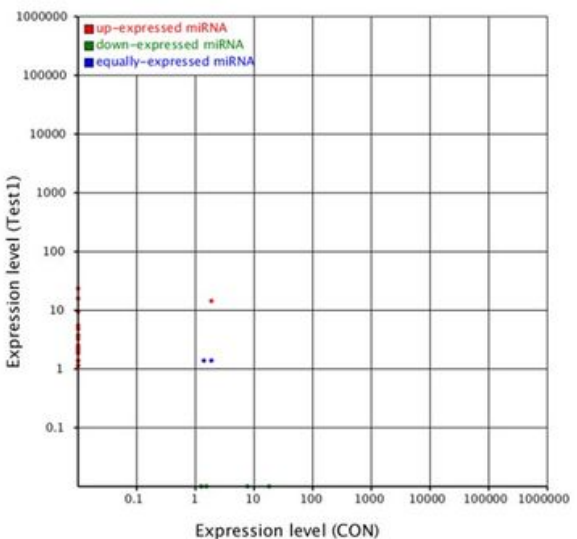

Scatter plot (control:x | treatment:y.

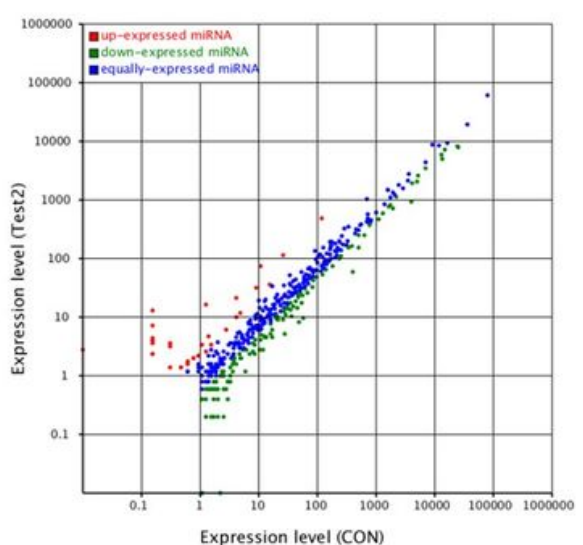

Scatter plot (control:x | treatment:y

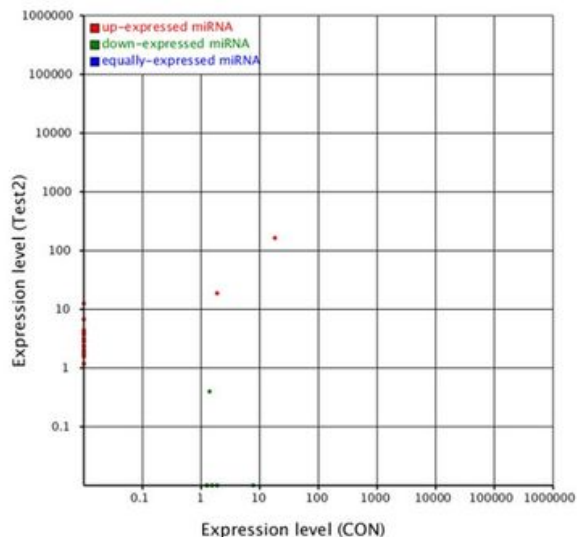

Scatter plot (control:x | treatment:y)

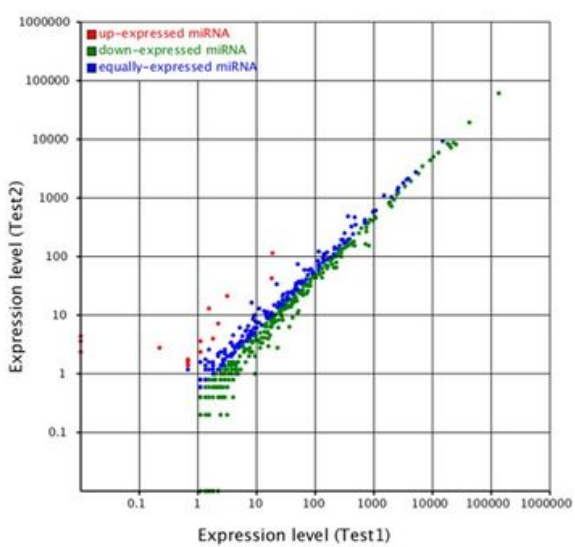

Scatter plot (control:x | treatment:y)

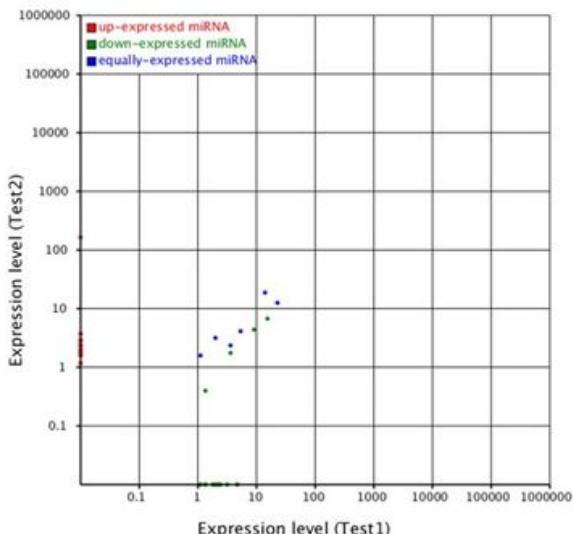

Figure 7

Differential expression of miRNAs. According to the number of reads counted by high-throughput sequencing, a comparison was drawn between the expression levels of conserved (a) and new (b) miRNAs at the three libraries. 


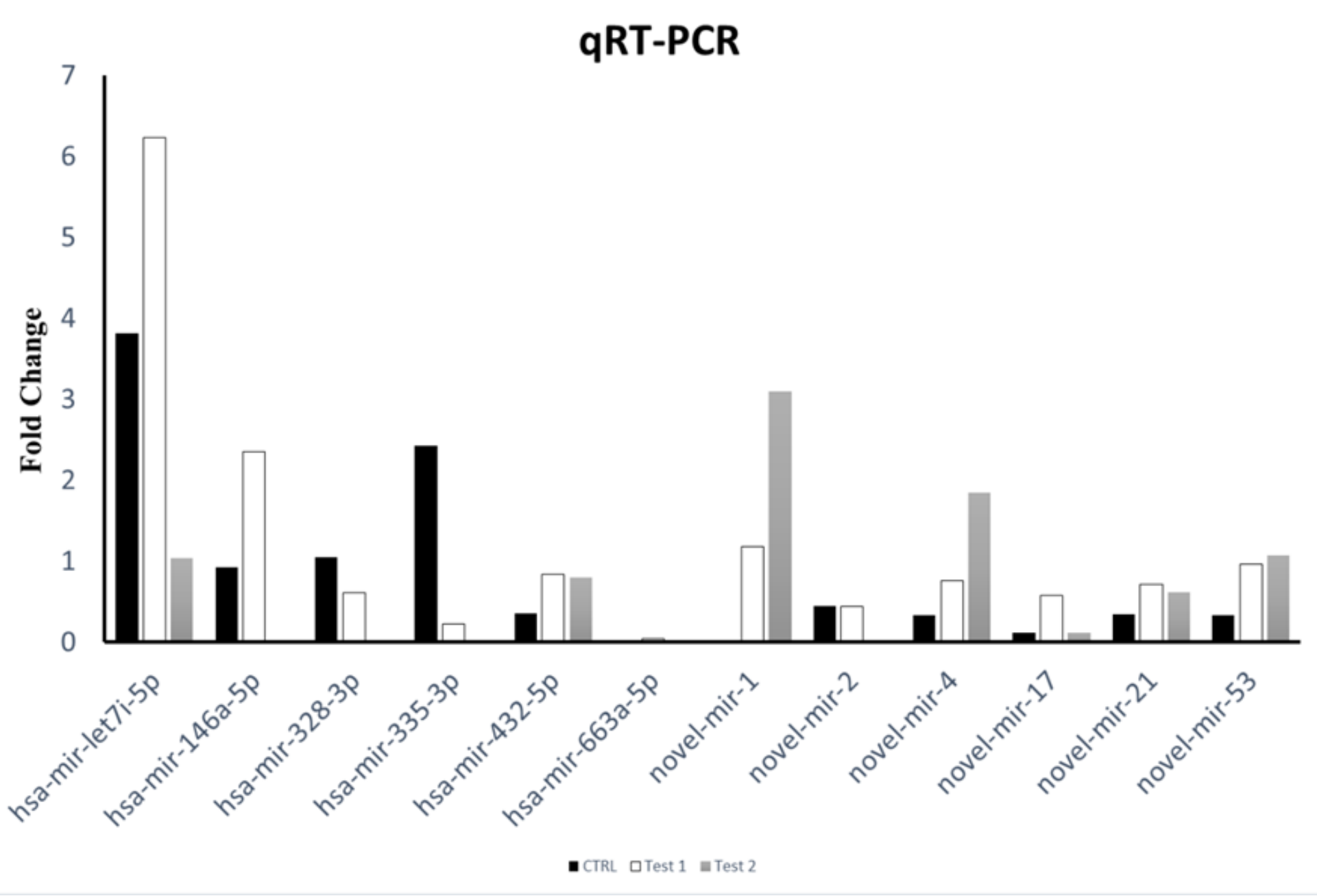

Figure 8

Q-PCR analysis of miRNA expression. Q-PCR technique was used to verify and measure the expression levels of six conserved miRNAs and six novel miRNAs in Control, Test 1 and Test 2 groups.

\section{Supplementary Files}

This is a list of supplementary files associated with this preprint. Click to download.

- Table7.docx

- Table3.docx

- Table2.docx

- Table1.docx

- Table4.docx

- Table6.docx

- Table5.docx

- controltest1.xlsx 
- test1.gene.GO.xlsx

- test2.gene.GO.xlsx

- S4.xlsx

- S1.xlsx

- controltest2.xIsx

- test1test2.xlsx

- test1test2highlighted.txt

- test1test2highlight.txt

- S2.txt

- CON1.gene.GO.xlsx

- miRNADiffExp.Expdiff.xls

- ctrltest1.txt 